\title{
Economic Impact of Quinoa Consumption in the Diet of University Students Case: ESPOCH Agroindustry Career
}

\section{Incidencia Económica del Consumo de Quinua en la Alimentación de Estudiantes Universitar- ios Caso: Carrera de Agroindustria ESPOCH}

VII International Congress of Science, Technology,

Entrepreneurship and Innovation (SECTEI 2020)

Corresponding Author:

B. Bravo

belen.bravo@espoch.edu.ec

Published: 26 August 2021

Production and Hosting by Knowledge E

(c) B. Bravo et al. This article is distributed under the terms of the Creative Commons Attribution License, which permits unrestricted use and redistribution provided that the original author and source are credited.

\section{B. Bravo, M. Miranda, and J. López}

Escuela de Ingeniería en Industrias Pecuarias. Facultad de Ciencias Pecuarias, Escuela Superior Politécnica de Chimborazo, Riobamba, Ecuador

\section{Abstract}

Quinoa is an ancestral plant, originally cultivated in the Andes. It is a product with exceptional nutritional value and it has been important in the socio-economic evolution of the Andean population. Food is considered a natural, ecological and economic product. Since quinoa has the same amount of protein as meat, it can complement people's daily food at a very low cost. The objective of this work was to carry out market research to determine the knowledge of university students about the protein value of quinoa in their diet and its purchasing power. The design was semi-experimental and descriptive. The study population was students of the Agroindustry degree of the Faculty of Livestock Sciences of the Higher Polytechnic School of Chimborazo. Data were collected through a questionnaire, which contained ten open and closed questions. 192 people were surveyed. Data were also collected through direct observations in the food laboratory. The results indicated a high level of ignorance of the benefits of quinoa. A lack of knowledge about quinoa can result in smaller economic benefits for those who produce this high protein food, which in most cases are indigenous communities.

Keywords: economic, consumption, quinoa, incidence.

\section{Resumen}

El presente trabajo, tiene por objetivo realizar una investigación de mercado, para determinar el conocimiento de los estudiantes universitarios, sobre el valor proteico de la quinua en su alimentación y el poder adquisitivo de la misma. El diseño es de tipo semi experimental y descriptiva. La población en estudio, son estudiantes de la carrera de Agroindustria de la Facultad de Ciencias Pecuarias de la Escuela Superior Politécnica de Chimborazo; para la recolección de datos se utilizó la técnica de la encuesta, apoyado en el cuestionario de la encuesta, como instrumento, la cual contiene diez preguntas abiertas y cerradas, basados en los objetivos de la investigación, se consideró una muestra de 192 personas, con la finalidad de obtener datos importantes que han sido analizados y explicados de forma descriptiva en el proceso, así mismo la observación directa que se realizó en el laboratorio de alimentos, mediante pruebas que se realizaron. La quinua es una planta ancestral, cultivada originariamente en los Andes, producto con excepcional valor nutritivo, e importante evolución socio económica de la población Andina. Alimentariamente es considerado un producto natural, ecológico y económico, ya que tiene la misma cantidad de proteína como la carne, 
puede complementar el alimento diario de cada persona a un costo muy bajo. Los resultados obtenidos, permitieron identificar el nivel de desconocimiento de los beneficios de la quinua, dando como resultado el mínimo impacto económico en quienes producen este alimento proteico, que, en la mayoría de los casos, son comunidades indígenas que buscan emprender.

Palabras Clave: economía, consumo, quinua, incidencia.

\section{Introducción}

La Quinua en su nombre científico Chenopodium quínoa Willd es un producto autóctono cultivada en la zona interandina, consumida por nuestros antepasados por su alto valor nutricional, quienes aprovecharon de un modo integral de sus nutrientes. Su consumo reemplazaba al de las proteínas animales, considerada una excelente fuente de nutrientes para el ser humano, en la actualidad se está reivindicando la imagen de la quinua, por las investigaciones realizadas, lo nominan como un alimento completo.

A pesar de que la quinua presenta grandes ventajas para la nutrición humana, los productos de quinua que han llegado a tener preferencia en el mercado son muy pocos, especialmente en Ecuador [1].

La mala alimentación que se genera en la juventud de hoy en día, es una consecuencia de la escasa información nutricional que se ha fomentado en los jóvenes, provocando una mínima incidencia económica en el consumo, es por esto que la presente investigación tiene como objetivo realizar una investigación de mercado, con la finalidad de determinar el conocimiento que tienen los estudiantes universitarios, sobre el valor proteico de la quinua en su alimentación y el poder adquisitivo de la misma, fomentando así el consumo de este cereal en diversas preparaciones de modo que la sociedad en especial jóvenes universitarios puedan tener mejores hábitos alimenticios [2]. La poca socialización de los beneficios de la quinua, provoca que se minimice el impacto económica de la misma.

\subsection{Historia de la quinua}

Según evidencias arqueológicas del norte chileno, la quinua fue utilizada 5000 años antes de Cristo, mientras que hallazgos en la zona de Ayacucho, en el Perú, indicarían que la domesticación de la quinua ocurrió incluso 2 mil años antes. Sin embargo, son pocas las evidencias arqueológicas, lingüísticas, etnográficas e históricas sobre la quinua. Por el contrario, sí existen evidencias claras de la distribución de los parientes silvestres, lo que posiblemente demuestra que su domesticación tomó mucho tiempo, 
en un proceso que probablemente se inició como una planta usada por sus hojas en la alimentación y luego por las semillas. Posteriormente, la especie fue adaptada a diferentes condiciones agroclimáticas, haciendo que la planta presente una amplia adaptación desde el nivel del mar hasta los 4000 m.s.n.m. [3].

Cárdenas [4] manifiesta de hallazgos de semillas de quinua en las tumbas indígenas de Tarapacá, Calama, Tiltel y Quillagua, demostrando este hecho que su cultivo es de tiempo muy remoto, mientras Patiño [5], menciona que, en sus revisiones sobre La Paz, se habla de la quinua como una planta que servía de alimento a los indígenas hay igual Heisser y Nelson [6] indican hallazgos arqueológicos en Perú y Argentina alrededor del inicio de la era cristiana. Según Estrella, aporta que por sus cualidades alimenticias y medicinales la quinua fue un alimento muy apreciado por nuestras poblaciones aborígenes. Según el criterio de varios autores compartimos la idea que la quinua es un alimento de tiempos muy remotos.

\subsection{Descripción de la quinua}

La quinua es una planta anual, dicotiledónea, usualmente herbácea, que alcanza una altura de 0,2 a 3,0 m. Las plantas de la quinua pueden presentar diversos tamaños, formas y colores que van del amarillo opaco, variando al casi blanco a rosa, naranja o de rojo a púrpura y negro, y colores intermedios entre estos. El tallo principal puede ser ramificado o no, depende del eco tipo, raza, densidad de siembra y de las condiciones del medio en que se cultiven, es de sección circular en la zona cercana a la raíz, transformándose en angular a la altura de las ramas y hojas. Se puede decir que algunos tipos de granos de trigo podrían acercarse a la riqueza de proteínas de la quinua, pero cereales tales como la cebada, el maíz y el arroz generalmente tienen menos de la mitad de sus proteínas. La quinua cuenta con un buen balance de aminoácidos a partir de los cuales se generan las proteínas, constituyéndose en un alimento de fácil digestión y se puede hacer germinar en poco tiempo. Su sabor recuerda bastante al del arroz integral, aunque su textura es mucho más fina recordando al cuscús, siendo en la antigüedad el alimento básico de los Incas durante miles de años hasta la llegada de los conquistadores, que sustituyeron su cultivo por el de maíz y patatas. En la actualidad vuelve a cultivarse en los Andes, en Inglaterra, y algunas de sus variedades, en diversos países.

Según Mújica [7], la quinua está ubicada dentro de la sección Chenopodia, las hojas son de carácter polimórfico en una sola planta; las basales son grandes y pueden ser romboidales o triangulares, mientras que las hojas superiores generalmente alrededor de la panoja son lanceoladas [8]. Su color va desde el verde hasta el rojo, pasando por el amarillo y el violeta, según la naturaleza y la importancia de los pigmentos. Son 
dentadas en el borde pudiendo tener hasta 43 dientes. Contienen además gránulos en su superficie dándoles la apariencia de estar cubiertas de arenilla [9-11].

Es necesario y sustancial diferenciar la variedad Quinua Real de la variedad Quinua Dulce. La primera es producida solamente en Bolivia, en tierras y salares que contienen una contextura apropiada para la producción de Quinua Real; en cambio, la segunda variedad se produce en la parte norte de La Paz, así también es producida en muchos países del continente sudamericano y americano, especialmente en Perú, Ecuador, México y en estado de Colorado (Canadá).

\subsection{Cultivo de la quinua}

Nos remontaremos a la antigüedad en donde la quinua es un pseudocereal originario del altiplano andino de América del Sur. Utilizada por el pueblo Inca, quienes lo denominaron 'El Grano Madre' venerándola como una planta sagrada. Los incas basaron buena parte de su supervivencia en el hecho de que la quinua puede cultivarse perfectamente a grandes alturas, ya que soporta sequías y no necesita de suelos ricos en nutrientes. La quinua se cultivaba de acuerdo con los rituales ancestrales y de una manera limpia y sin alteraciones ni manipulaciones genéticas. Los españoles, al ver la gran connotación religiosa y la autosuficiencia que algunos pueblos aborígenes asignaban a la quinua, decidieron exterminarla quemando las plantaciones. Tanto el cultivo como el consumo fueron terminantemente prohibidos y se tomó a la quinua de manera despectiva como 'alimento para salvajes' [12].

En el 2008, en el PRONALEG-GA del INIAP se inicia un programa de mejoramiento de quinua por hibridación, el principal objetivo es la precocidad, tamaño grande del grano, resistencia a enfermedades foliares causada por hongos y rendimiento [13].

La FAO, que designó 2013 como año internacional de la quinoa, como una de las principales plantas cultivables por sus grandes propiedades, sus múltiples usos y representar una alternativa potencial para solucionar la desnutrición en grandes áreas del planeta [14]

El cultivo de Ch. quinoa W. es una buena alternativa de futuro frente a la emergente necesidad en el ámbito global de identificar cultivos que tengan el potencial de producir alimentos de calidad. Las Naciones Unidas (UN) declaró el 2013 como el 'Año Internacional de la Quinoa (AIQ)'.

El objetivo del AIQ es: 'Centrar la atención mundial sobre el papel que juega la biodiversidad de la quinua y su valor nutricional en la seguridad alimentaria y en la erradicación de la pobreza, en apoyo al logro de los Objetivos de Desarrollo del Milenio' (Organización de las Naciones Unidas para la Alimentación y la Agricultura [14]. Por sus bondades nutritivas y su versatilidad agronómica, la FAO comunicó que Ch. quinoa W. 
constituye un cultivo estratégico que contribuirá a la seguridad y soberanía alimentaria global.

Especialmente en aquellos países donde la población no tiene acceso a alimentos ricos en proteínas, o donde la producción de alimentos es limitada. El interés científico que ha generado este cultivo en el ámbito mundial se traduce en la implantación de nuevas líneas de investigación: Estudios de calidad nutricional, de rendimiento, de mejoramiento genético, de resistencia a plagas, etc.

\subsection{Selección del campo}

El campo que se empleará en el cultivo de quinua debe ser elegido considerando los siguientes criterios:

1. Requerimientos agroclimáticos del cultivo

2. Rotación La rotación debe considerar factores como presencia de malezas, fertilización residual, plagas, pesticidas residuales y preparación de suelo, disponibilidad de agua y otros que se considere importantes y propios de la zona donde se establecerá el cultivo. Se recomienda sembrar quinua:

3. Suelos: Son deseables los de textura franca, con alto contenido de materia orgánica, con una profundidad de 60 a $90 \mathrm{~cm}$ y con un buen drenaje y un $\mathrm{pH}$ neutro o cercano a la neutralidad.

4. Distanciamiento o aislamiento Si se conducen semilleros, dependiendo de la categoría de semilla producida, se elegirán campos aislados o distanciados de otros campos [15].

\subsection{Manejo del cultivo}

Es importante considerar la adaptación de las variedades a las diferentes condiciones de clima y altitud; si bien la quinua tiene amplia adaptación como especie, muchas variedades tienen adaptación muy específica a ciertos ambientes [16]. En algunos ambientes crecen vegetativamente sin llegar a fructificar o son de ciclos tan cortos que están listas a cosechar en pleno periodo de lluvias con bajos rendimientos y calidad de granos. Por lo tanto, la elección de la variedad es muy importante. Los criterios de elección pueden ser muchos y con diferentes prioridades, pero destacan: Alto rendimiento; madurez; las variedades precoces o semiprecoces rinden menos que las variedades tardías, aunque ofrecen un mecanismo importante para escapar de enfermedades, bajas o altas temperaturas, sequías, y baja disponibilidad de nutrientes en el suelo; las variedades tardías necesitan condiciones favorables durante la época 
de crecimiento, que generalmente no se presenta en todas las situaciones; área de adaptación; la variedad debe estar adaptada a la zona en la que se va Producir [17]. Cada zona tiene sus propias características de clima, suelo, población patógena, etc.; Mercado-calidad.

Asociado con el color de los granos, contenido de proteína del grano, contenido de saponina del grano, tamaño de grano y otros que demande el mercado y el uso final de la quinua; altura de planta. Plantas entre 1 y $1.20 \mathrm{~m}$ o aquella altura que no dificulte la aplicación de prácticas culturales y facilite el proceso de cosecha; resistencia al tumbado o acame. El tumbado reduce el rendimiento y la calidad del grano, además de incrementar los costos de cosecha [18].

\subsubsection{Propiedades nutricionales}

Las bondades peculiares del cultivo de la quinua están dadas por su alto valor nutricional. El contenido de proteína de la quinua varía entre 13,81 y 21,9\% dependiendo de la variedad. Debido al elevado contenido de aminoácidos esenciales de su proteína, la quinua es considerada como el único alimento del reino vegetal que provee todos los aminoácidos esenciales, que se encuentran extremadamente cerca de los estándares de nutrición humana establecidos por la FAO. Al respecto Risi [19] acota que el balance de los aminoácidos esenciales de la proteína de la quinua es superior al trigo, cebada y soya, comparándose favorablemente con la proteína de la leche. Su composición del valor nutritivo de la quinua en comparación con la carne, el huevo, el queso y la leche.

Table 1

Composición del valor nutritivo de la quinua en comparación con alimentos básicos (\%).

\begin{tabular}{|c|c|c|c|c|c|c|}
\hline Componentes & \multirow{2}{*}{$\begin{array}{l}\text { Quinua } \\
13\end{array}$} & \multirow{2}{*}{$\begin{array}{l}\text { Carne } \\
30\end{array}$} & \multirow{2}{*}{$\begin{array}{l}\text { Huevo } \\
14\end{array}$} & \multirow{2}{*}{$\begin{array}{l}\text { Queso } \\
18\end{array}$} & \multirow{2}{*}{$\begin{array}{l}\text { Leche } \\
\text { Vacuna } \\
3,5\end{array}$} & \multirow{2}{*}{$\begin{array}{l}\text { Leche } \\
\text { Humana } \\
1,8\end{array}$} \\
\hline Proteínas & & & & & & \\
\hline Grasas & 6,1 & 50 & 3,2 & & 3,5 & 3,5 \\
\hline $\begin{array}{l}\text { Hidratos de } \\
\text { carbono }\end{array}$ & 71 & & & & & \\
\hline Azúcar & & & & & 4,7 & 7,5 \\
\hline Hierro & 5,2 & 2,2 & 3,2 & & 2,5 & \\
\hline $\begin{array}{l}\text { Calorías } 100 \\
\mathrm{~g}\end{array}$ & 350 & 431 & 200 & 24 & 60 & 80 \\
\hline
\end{tabular}

Fuente: Informe agroalimentario, 2009. MDRT BOLIVIA.

La calidad nutricional de un producto depende tanto de la cantidad como de la calidad de sus nutrientes. La quinua según Bo y Morón [20], citados por Jacobsen y Sherwood [21] presenta el valor de $13,81 \mathrm{~g} / 100 \mathrm{~g}$ de materia seca que, comparado con trigo Manitoba 16,0 g/100 g y Triticale $15,0 \mathrm{~g} / 100 \mathrm{~g}$, no tiene un alto contenido de 
proteínas. En general, si se hace una comparación entre la composición de nutrientes de la quinua y los del trigo, arroz y maíz (que tradicionalmente se mencionan en la bibliografía como los granos de oro) se puede corroborar que los valores promedios que reportan para la quinua son superiores a los tres cereales en cuanto al contenido de proteína, grasa y ceniza [11]. La literatura en nutrición humana indica que sólo cuatro aminoácidos esenciales probablemente limiten la calidad de las dietas humanas mixtas.

Estos aminoácidos son la lisina, la metionina, la treonina y el triptófano. Es así que, si se compara el contenido de aminoácidos esenciales de la quinua con el trigo y arroz, se puede apreciar su gran ventaja nutritiva: por ejemplo, para el aminoácido lisina, la quinua tiene 5,6 gramos de aminoácido/16 gramos de nitrógeno, comparados con el arroz que tiene 3,2 y el trigo $2,8 \mathrm{~g}$ [22].

\subsection{Proteínas}

Bojanic [3] mantiene que entre el 16 y el $20 \%$ del peso de una semilla de quinua lo constituyen proteínas de alto valor biológico, entre ellas todos los aminoácidos, incluidos los esenciales, es decir, los que el organismo es incapaz de fabricar y por tanto requiere ingerirlos con la alimentación. Los valores del contenido de aminoácidos en la proteína de los granos de quinua cubren los requerimientos de aminoácidos recomendados para niños en edad preescolar, escolar y adultos [14]. No obstante, la importancia de las proteínas de la quinua radica en la calidad. Las proteínas de quinua son principalmente del tipo albúmina y globulina. Estas, tienen una composición balanceada de aminoácidos esenciales parecida a la composición aminoacídica de la caseína, la proteína de la leche. Se ha encontrado también que las hojas de quinua tienen alto contenido de proteínas de buena calidad. Además, las hojas son también ricas en vitaminas y minerales, especialmente en calcio, fósforo y hierro.

\subsection{Beneficios}

1. Posee un alto nivel de proteínas, puede contener hasta un $23 \%$.

2. Está compuesta por: Minerales (calcio, hierro, magnesio), vitaminas (C, E, B1, B2 y niacina) y fósforo.

3. Es rica en aminoácidos, que influyen en el desarrollo cerebral.

4. Su contenido en grasa es rico en Omega 6.

5. Es una importante fuente de fibra soluble e insoluble.

El beneficio de estos granos andinos, es que no tienen gluten, importante para las personas que sufren la enfermedad denominada celiaca, que es una alteración del 
intestino delgado por la intolerancia al gluten de los cereales. La misma que ocasiona la mala absorción de nutrientes: Lípidos, glúcidos, prótidos, vitaminas y minerales. Los estudios de las propiedades nutraceúticas de estos granos, continúan en especial en los contenidos de minerales, vitaminas, grasas, antocianinas, fibra, antioxidantes, etc. $[22,23]$.

\subsection{Productos elaborados en base a la quinua}

1. Barras energéticas: Que son comercializadas a manera de snacks al igual que otros cereales. Por ejemplo, la marca Keenwah elabora dos presentaciones de estos snacks en base a quinoa (como es conocido el grano andino en Estados Unidos): Con nueces y avellanas.

2. Cajas de cereales: Al igual que los populares cornflakes, nuestra quinua es comercializada en hojuelas. La popular marca Cheerios ha lanzado la presentación 'Ancient grains' que incorpora entre otros cereales la quinua. La marca Cocomama, por ejemplo, la combina con otras frutas en sus presentaciones, así existen: Quinoa con bluberries, quinoa con plátano y canela y quinoa con naranja y cranberry.

3. Yogurt: Al igual que las populares copitas de yogurt personales de la marca Laive - Gloria en nuestro país, la marca Kellogs sacó el yogurt con copa de granos de quinua.

4. Comidas preparadas: Varias marcas como Natures's earthly choice y Pereg mezclan la quinua con vegetales, arroz y hasta champiñones para una cocción rápida y fácil de servir. Otras no muy comunes que llamaron nuestra atención fueron la sopa preparada en base a quinua y la polenta congelada en base a quinua. Por último, la marca happytot elabora comidas preparadas para niños pequeños en base a quinua.

5. Harina: Marca como Bob's Red mill o Ancient Harvest entregan al consumidor la quinua en harina para la elaboración de postres en base este grano.

6. Pasta: En coditos, linguini y spaguetti entre otras presentaciones de pasta, las marcas Ancient Harvest, Natur'es earthly choice y Pereg elaboran pasta en base a quinua.

7. Hamburguesas: Las populares patties como son conocidas en estados Unidos pueden venir congeladas y empanizadas con quinua.

8. Chocolates: Especialmente con chocolate negro o presentaciones especiales contienen granos de quinua lo que le da un sabor crujiente. 
9. Galletas: Acompañadas de frutas como berries y arándanos o chispas de chocolate.

10. Bebidas: Jugos y smoothies en base a quinua son combinados con diferentes frutas. La marca Nuwi tiene diversas presentaciones [24, 25].

\subsection{Otros productos elaborados}

En Ecuador existen antecedentes de producción y comercialización de productos en base de quinua a nivel industrial como son:

1. Mezclas de harina de quinua con avena: Quinua-avena.

2. Mezcla de harina de quinua con soya: Quinua-soya.

3. Productos infantiles tipo papilla en base de cereales que incluyen quinua.

4. Bebidas en base de cereales que incluyen quinua y sabores de frutas.

5. Cereales para desayuno que incluyen expandidos (reventados) de quinua.

6. Pan con porcentaje de sustitución de harina de quinua: panaderías exclusivas.

7. En menor escala y solamente en almacenes de productos producidos por campesinos (Comercio justo), se comercializan fideos con algún porcentaje de sustitución [26].

\subsection{Comercialización de la quinua}

Respecto al proceso de Industrialización de la quinua, en el país se manejan procesos simples y semi complejos. La gama ecuatoriana de productos elaborados con quinua es restringida y limitada a la quinua desaponificada, perlada y alimentos intermedios (hojuelas, insuflados y harinas de quinua), y muy limitadamente la papilla para niños. En Ecuador, el procesamiento de la quinua se concentra en el lavado y/o escarificado (perlado) del grano para eliminar la saponina, la elaboración de harinas; hojuelas y el desarrollo de nuevos productos como galletas, pan, graneados, etc. [7, 26].

\subsection{Incidencia económica}

La producción de quinua en el país volvió a reducirse este año. Tras el 'boom' de ese cereal, que se produjo en el 2013, los agricultores ahora están desmotivados por la caída del precio en el mercado internacional y la fuerte competencia en precios con la producción de Perú y Bolivia. En el 2016, en Chimborazo había 3539 agricultores que 
destinaron casi la totalidad de sus campos al cultivo, pero para el 2017 el número se redujo a 2447 agricultores y se prevé que para finales de este año incluso baje más. La decepción de los agricultores se produjo debido a las altas expectativas que se prometían respecto a la semilla, cuando en el 2013 se declaró el año internacional de la quinua. Con ese anuncio surgió una campaña para motivar la siembra y el consumo, que alcanzó su punto más alto en el 2015. Ese año en el país se sembraron 7886 hectáreas con quinua y la meta nacional era de 10.000. El Ministerio de Agricultura y Ganadería (MAG) entregó semillas certificadas y kits que contenían insumos orgánicos para la siembra en 19 comunidades [28].

La pobreza ha hecho a las comunidades indígenas que se dedican a la producción de la quinua y elaboración, una población vulnerable con limitadas oportunidades de desarrollo. En el pasado el cultivo de quinua ha estado fuertemente ligado a la ganancia que representaba para terceros y su crecimiento Empresarial; en la actualidad se ha concentrado mayormente en la inclusión social y en que los ingresos sean distribuidos equitativamente para las comunidades, así como también el mejoramiento en la calidad de vida de cada uno de sus partícipes. La inadecuada comercialización debida en su mayor parte al escaso valor agregado que ofrecen las industrias que comercializan este producto disminuye su comercialización dando origen al consumo de otro tipo de alimentos y en su mayor parte al consumo de comida chatarra [29].

\section{Materiales y Métodos}

\subsection{Descripción}

La investigación fue ejecutada en la Escuela Superior Politécnica de Chimborazo (Espoch), a los estudiantes de la carrera de Ingeniería de Agroindustria, primer y segundo semestre, periodo Abril- agosto 2018. Se aplicó el método descriptivo, cualitativo y cuantitativo.

Descriptivo: Puesto que permitió evaluar algunas características de consumo y conocimiento de la quinua de la población objeto de estudio, así como describir el comportamiento de las variables.

Cualitativo: Porque permitió conocer sobre la incidencia, importancia, beneficios y consumo de la quinua en los estudiantes. Este producto ofrece bondades nutricionales y proteicas que puede estar incluida en la dieta diaria de los estudiantes de la carrera de agroindustria, proporcionándoles una mejor calidad de vida.

Cuantitativo: Mediante un método estadístico, se manejó la información de la encuesta realizada, en los diferentes paralelos de la carrera, donde se obtuvo datos relevantes sobre la incidencia económica del consumo de la quinua en la alimentación de los estudiantes de la carrera de agroindustrias caso ESPOCH. 


\subsection{Instrumentos}

Para recabar los datos para esta investigación se formuló un cuestionario para la aplicación de la encuesta con diez preguntas abiertas y cerradas, con las respuestas obtenidas de varias preguntas, los estudiantes de la carrera de agroindustria, dieron a conocer la incidencia económica del consumo de la quinua; en esta investigación también se aplicó la técnica de observación, a través de ella se pudo analizar los conocimientos del grado proteico que aporta al cuerpo humano la quinua al momento de su consumo así como la frecuencia con la que se realiza.

\subsection{Procedimiento}

Para poder ejecutar la presente investigación se trabajó con un equipo de tres investigadores, el mismo que planificó la aplicación de las técnicas para recabar la información, así como la planificación de las demás actividades. Se ejecutó la encuesta a 100 estudiantes de la carrera de agroindustria tanto en jornada matutina como en jornada vespertina. A cada curso se aplicó una encuesta de diez preguntas respectivamente de respuestas de tipo cerradas y abiertas, estas últimas permitió obtener criterios personales de características sociales y económicas, en esta herramienta se manejó un margen de error del 5\%. Las encuestas fueron validadas por alfa de cronbach, con un resultado bueno de 0,820 , como se muestra en los estadísticos de fiabilidad procesados a través de SPSS.

\section{Table 2}

Resumen del procesamiento de los casos.

\begin{tabular}{|c|c|c|c|}
\hline & & $\boldsymbol{N}$ & $\%$ \\
\hline \multirow[t]{3}{*}{ Casos } & Válidos & 183 & 95,3 \\
\hline & Excluidos $\wedge a$ & 9 & 4,7 \\
\hline & Total & 192 & 100 \\
\hline
\end{tabular}

Fuete: Spss, eliminación por lista basada en todas las variables del procedimiento.

Table 3

Estadísticas de fiabilidad.

Alfa de Cronbach
0,820

Alfa de Cronbach basada en los
elementos tipificados
0,830

$\mathbf{N}$ de elementos 10

Para la observación directa se realizó un análisis de proteína en el laboratorio de alimentos de la Facultad de Ciencias Pecuarias, en el cual se planificó y ejecutaron 3 
tomas diferentes de 4 tipos de quinuas en la misma presentación, adicional se trabajó con un testigo para verificar las variaciones a obtener.

\section{Resultados y Discusión}

Los resultados obtenidos a partir de la aplicación de los instrumentos de recopilación de información fueron de gran ayuda para confirmar los objetivos de la investigación y concordar con varias investigaciones que se pudieron encontrar durante la recopilación de la información.

Los cereales ocupan el segundo lugar de consumo frente a los demás alimentos que ingieren la población objeto de estudio (Figura 1), de los cuales una la totalidad ha consumido quinua:

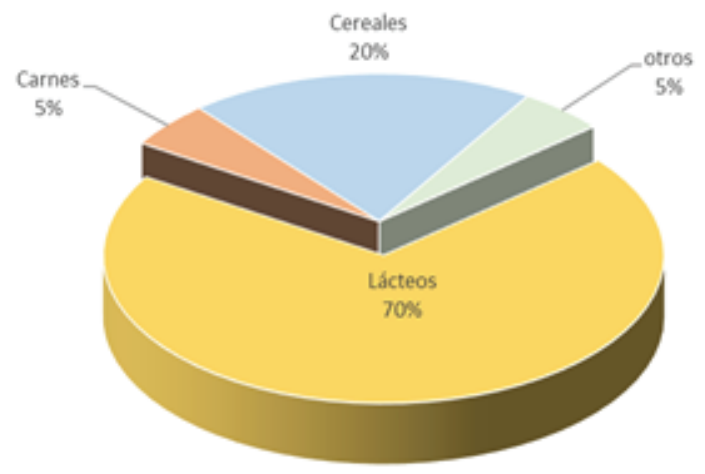

\section{Figure 1}

Tipo de alimentos consumidos. Fuente: Investigación de campo.

El problema no radica en el conocimiento del producto, sino más bien en los hábitos de consumo, puesto que la población investigada, apenas el 1\% consume este cereal diariamente y la gran mayoría (50\%), consume mensualmente (Figura 2), un nivel bajo a pesar que es uno de los alimentos considerados de oro por su bajo costo y alto valor nutricional, a pesar que una de las mayores razones de consumo de la quinua es simplemente por gusto acorde a la población investigada con un $40 \%$, seguido luego de la importancia nutricional un $30 \%$ y la imposición es la última razón considerara con un $10 \%$, la diferencia (20\%) es simplemente costumbre, a pesar de ello el $60 \%$ de la población si conoce el valor nutricional y los beneficios que aporta la quinua al consumirla (Figura 3).

La totalidad de la población investigada está en la posibilidad de adquirir este valioso cereal acorde a su presupuesto semanal (Figura 4).

La actual investigación se facilitó debido a que la población completa conoce la existencia del cereal, lo cual dispuso de forma adecuada el proceso de levantamiento 


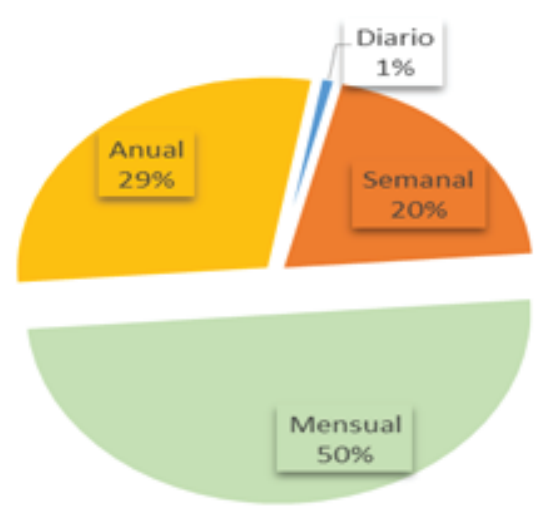

Figure 2

Frecuencia de consumo de la quinua. Fuente: Investigación de campo.

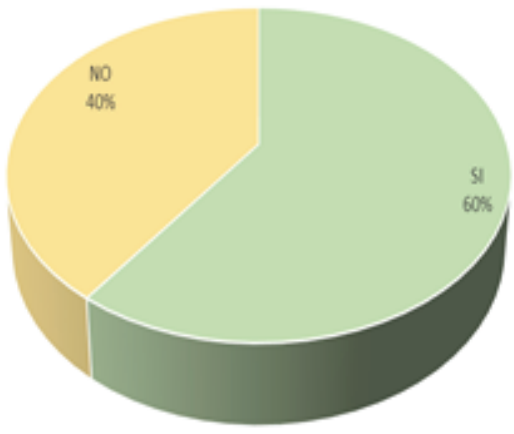

Figure 3

Conocimiento del valor nutricional y beneficios de la quinua. Fuente: Investigación de campo.

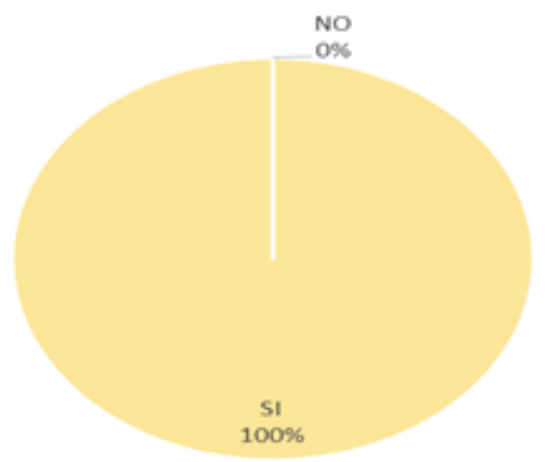

\section{Figure 4}

Poder adquisitivo de la quinua/presupuesto semanal. Fuente: Investigación de campo.

de información, así como su frecuencia de consumo, concordando con lo manifestado por Hancco y Laura [29] que estos cereales de alto valor proteico son remplazados por arroz o fideo por su facilidad de consumo, de ahí que apenas el $1 \%$ de la población investigada consume a diario, el $20 \%$ consume en forma semanal, la mitad el $50 \%$ consume en forma mensual y el $29 \%$ en forma anual. 
Fue transcendental conocer que apenas el $20 \%$ consume quinua por costumbre, el $40 \%$ porque gusta del alimento, el 10\% por imposición de su familia, y el $30 \%$ porque la quinua posee un alto valor nutricional. Al saber que un porcentaje positivo gusta de la quinua facilita la intención de compra del cliente lo que favorece a la comercialización del producto, en la investigación realizada por Bojanic [3] donde manifiesta que estos cultivos milenarios contribuyen y contribuirán a la seguridad alimentaria no solo de los países andinos, sino del mundo entero, garantizando una alimentación sana y balanceada siempre y cuando se la consuma de forma adecuada, al igual que menciona su bajo costo de adquisición y múltiples beneficios concordando en los costos con la investigación realizada por la Unesco en el año 2017.

En cuanto al conocimiento del valor nutricional y beneficios que posee la quinua, la mayoría de la población investigada (70\%) conocía sobre las propiedades, beneficios y valores nutricionales que posee la quinua, una de las razones por las que consumían, en la investigación realizada por Mujica, A. et al. Denominado 'Origen y descripción de la quinua'. En: Quinua.

Ancestral Cultivo Andino, Alimento del Presente y Futuro [8]. Permite conocer a profundidad los aportes nutricionales y beneficios para la salud, así como los diferentes usos alimenticios que se le pueda dar a la quinua, al ser conocedores la población de toda esta información, seguramente el incremento de consumo será notable, no solo en su forma natural, sino también en sus diferentes presentaciones, así también lo manifiesta la población investigada, pues, el $60 \%$ de la población si han consumido productos derivados de la quinua, la mayoría de las personas que adquieren y consumen el producto, lo hacen no sólo en forma directa, si no en sus diversas presentaciones alimenticias, varias de ellas en la investigación realizada por Tapia [9], que nos permite profundizar conocimientos sobre la sub explotación de este 'cereal de oro' las varias formas de presentación y el aporte alimenticio de cada una de ellas.

Toda la población tiene predisposición de consumo la quinua, y están prontos a recomendar el consumo por los valores nutricionales que posee. Peralta manifiesta que, por sus calidades nutritivas, la quinua es ideal para la alimentación de la población con altos y diferentes niveles nutricionales, como población resistente al gluten, mujeres en gestación, madres lactantes, niños y población de tercera edad, entre otros; un beneficio final destacado es el presupuesto de gastos semanal que destaca como algo principal en esta y otras investigaciones que concuerdan que las diferentes poblaciones investigadas están en la capacidad de adquirir como mínimo una libra semanal de quinua por su costo accesible y poca o nula dificultad que existe para adquirirla [30]. 


\section{Conclusiones}

Se ha determinado que la cantidad y frecuencia de consumo en la población investigada es media baja, a pesar del conocimiento ancestral de este cereal, mientras que el conocimiento de su valor nutricional es menor que el conocimiento de la existencia, sin embargo, existe, hay que considerar que su preparación es lo que dificulta para su consumo, de donde nace la preferencia de consumo por otros productos incluso cereales más fáciles de adquirirlos y consumirlos.

La frecuencia de consumo de la quinua en promedio es una vez al mes a pesar de su fácil poder adquisitivo, su precio bajo y el rendimiento que tiene una vez preparado, esta investigación permite tener la premisa que es la falta de incentivo y falta de valor desde los hogares por el consumo de este producto, los sembríos son amplios con pocos réditos económicos, pero si se incrementa la comercialización del producto se podría mejorar tanto ingresos a productores como disminuir gastos desmesurados en otros productos sin mucho aporte nutricional de los consumidores.

La intención para el consumo de quinua se pudo razonar como aporte para el incremento de los índices de comercialización del producto, a través del marketing directo, considerando que el valor agregado es el beneficio que aporta a la salud con sus múltiples nutrientes identificados en su análisis de laboratorio.

\section{References}

[1] Estrella E. El Pan de América: etnohistoria de los alimentos aborígenes en el Ecuador. Tercera Edición transcrita y corregida de la 1ra. Impresión madrileña 1986. Quito: FUNDACYT; 1998. 257 p.

[2] Quispe RL. Galeon.com. 2000. Available from: http://alimentos-andinos.galeon.com/ quinua.html

[3] Bojanic A. La Quinua: Cultivo milenario para contribuir a la seguridad alimentaria mundial. Rome: FAO: 2011.

[4] Cardenas M. Descripción preliminar de las variedades de Chenopodium quinoa de Bolivia. Cochabamba: Universidad Mayor de San Simón; 1944. Enseñanza Superior Agronómica.

[5] Patiño VM. Plantas cultivadas y animales domésticos en América equinoccial. Cali: Imprenta departamental; 1964.

[6] Heisser CB, Nelson DC. On the origin of the cultivated chenopods (Chenopodium). Genetic. 1974;78:503-505.

[7] Mujica A. Cultivos marginados: Otra perspectiva de 1492. Hernández J, Bermejo J, Leon J, editors. Rome: FAO; 1992. 
[8] Mujica A, Izquierdo J, Marathee J. Ancestral cultivo andino, alimento del presente y futuro. Lima: FAO.

[9] Tapia M. Cultivos Andinos subexplotados y su aporte a la alimentación. Santiago: Instituto Nacional de Investigación Agraria y Agroindustrial INIAA - FAO; 1990.

[10] Dizes J, Bonifacio A. Estudio en microscopia electrónica de la morfología de los órganos de la quinoa (Chenopodium quinoa W.) y de la cañahua (Chenopodium pallidicaule A.) en relación con la resistencia a la sequía. Actas del VII Congreso Internacional sobre Cultivos Andinos; 1991 July 4-8; La Paz, Bolivia.

[11] Rojas W. Multivariate analysis of genetics diversity of bolivian quinoa germoplasm. Food Reviews International. 1993;19(1):923.

[12] Flores J, Mamani E, Alarcón V, Paco V, Rojas W. Caracterización de los conocimientos tradicionales asociados a la agrobiodiversidad en Coromata Media y Santiago de Okola. Informe Octubre 2007 - Junio 2008. NUS IFAD II. Fundación PROINPA; 2008; La Paz, Bolivia.

[13] INIAP. Informe Anual Técnico. Quito: INIAP; 1967.

[14] FAO. Necesidades de Energía y de proteínas. Serie de Informes Técnicos 724. Ginebra: Organización Mundial de Salud; 2000.

[15] Wahli C. Quinua, hacia su cultivo comercial. Quito: Latinreco S.A.;

[16] Villena AG. Sistemas de cultivo de la quinua (Chenopodium quinoa Willd.) y su efecto en el rendimiento y calidad en condiciones de verano en La Molina [Tesis Ing]. Lima: Agrónomo; 2011.

[17] Gandarillas H, Nieto C, Castillo R. Razas de Quinua en Ecuador. Boletín Técnico No. 67. Programa de Cultivos Andinos. Estación Experimental Santa Catalina, INIAP. Quito: 1989.

[18] IBCE. Perfil de Mercado Granos Nativos Quinua y Amaranto. La Paz; 2009.

[19] Risi J, Galwey NW. Advances in applied biology. Vol. 10. Coaker TH, editor. London: Academic Press; 1984. The Chenopodium grains of the Andes: Inca crops for modern agricultura.

[20] Morón C. 1999. Memorias reunión técnica y taller de formulación de proyectos regionales sobre producción y nutrición humana en base a cultivos andinos. Perú; FAO: 2008. Importancia de los cultivos andinos en la seguridad alimentaria y nutrición.

[21] Jacobsen S, Sherwood S. Cultivo de Granos Andinos en Ecuador. Informe sobre los rubros quinua, chocho y amaranto. Organización de las Naciones Unidas para la Agricultura y la Alimentación (FAO), Centro Internacional de la Papa (CIP), Catholic Relief Services (CRS). Quito:2002.

[22] Repo-Carrasco R. Introducción a la ciencia y tecnología de cereales y de granos andinos. Lima; 1998. 
[23] ERPE, Raffauf M. Quinua Orgánica. Riobamba; 2000.

[24] Mayor M. Proexpansion.com. 2014. Obtenido de http://proexpansion.com/es/articl es/901-alimentos-en-base-a-quinua-algunos-presentaciones-que-cautivan-al-con sumidor-norteamericano.

[25] García G. Diagnóstico de la situación actual y perspectivas de la producción de quinua en Ecuador [Tesis Ing. Agrónomo]. Riobamba: Facultad de Ingeniería Agronómica; 1984.

[26] Villacrés E. Caracterización física, nutricional y funcional de papas nativas (Solanum tuberosum ssp.) para orientar sus usos en Ecuador. Revista Latinoamerica de la Papa. 2009;15(1):52-54.

[27] La quinua perdió protagonismo por baja en el mercado mundial. Revista Líderes. 2018.

[28] UNESCO LIMA. Obtenido de Sembrar quinua orgánica para reducir la pobreza en Ios Andes. Lima: UNESCO; 2017.

[29] Hancco G, Laura V. Revalorización de los granos Andinos: Quinua y Kañihua, a través del método Healthcom, para mejorar la alimentación de los estudiantes del distrito de Muñoa, provincia Melgar, Puno-2016 [Tesis de grado]. 2017.

[30] Peralta E. A favor de la Quinua o quinoa...se hace camino al andar en Ecuador. Revista Raíces Productivas.2006;54:16. 